\title{
Driving Progress Through Sports - Lean In and Act Now!
}

\author{
EXERCISE IS MEDICINE
}

\begin{abstract}
Anna Erat
It is well known that girls who play sports stay in school longer and reach higher levels of education. They suffer fewer health problems, enter the labor force at higher rates and are more likely to take up leadership positions. A study by EY shows that more than $94 \%$ of female C-Suite executives today played competitive sport, and over 50\% played at university level [1]. Furthermore, supporting girls and women in sport leads to stronger women, stronger communities, and significantly contributes to economic growth overall. Indeed, if we were to empower women in our economies through for instance sports, we could add an amount of \$12trn to the global economy by 2025 according to research by Mc Kinsey and the Peterson Institute [2,3].
\end{abstract}

"I firmly believe that sport is one of the most powerful platforms for promoting gender equality and empowering women and girls.» $\mathrm{Q}(\mathrm{IOC}$ president Thomas Bach, 2018)

However, increasing the number of girls and women in competitive sports does not simply "happen". Policies on athletic programs and funding are of essence. Title IX for instance, is a public policy that was introduced in the U.S. in 1972 that requires organizations to invest in male and female athletes equally in order to receive federal financial assistance. Since its introduction, there has been a $545 \%$ increase in the percentage of women playing college sports and a 990\% increase in the percentage of women playing high school sport [1,4]. In Switzerland, Swiss Olympic has also initiated various crucial programs to support girls and women in sports. One such important initiative is "Frauen und Spitzensport" which also addresses medical aspects of women in sports, with the expert conference in June 2020 at «Haus des Sports» leading the way.

The importance of the initiative and its medical perspective is great, as gender specific issues ranging from hormonal cycles to pregnancy and injury patterns have long been ignored. In fact, only a small percentage of all studies on training, regeneration, performance and wellbeing address female athletes. Thus, we have little data an evidence to draw from while taking care of female athletes. This issue of the journal is therefore dedicated to the over-due topic of females in sports and sports medicine. Here our distinguished researchers address a wide array of gender-specific topics, ranging from nutrition and sports psychology to pregnancy and the impact of the menstruation cycle on performance.

If we look at the entire lifecycle of sports-medicine, however, we cannot only address the researched 
population, but also the researcher itself. In this issue, a study in Switzerland shows the underrepresentation of female researchers and keynote speakers in national sports-medicine congresses. Clearly, there is a myriad of reasons for the underrepresentation on micro- meso- and macro-levels, including individual, educational and cultural aspects, as well as social, economic and policy frameworks. It is important to analyze these reasons, as we need to learn from the past and use the captured knowledge to allow positive change for the future. We should use this momentum to find new solutions rather than to dwell the past. I am therefore delighted to interview three highly accomplished international female leaders and athletes to discuss their experiences and proposed actions to advance women in competitive sports and to drive progress.

\section{Guest editor}

Dr. Anna Erat MD/PhD is a former internationally competitive junior alpine skier with a clinical specialization in internal medicine, sports medicine and preventive medicine. Before her medical training she conducted pre-and post-doctoral research at Harvard Medical School and the Swiss TPH. She is currently a national team doctor for the Women's U-18 Swiss Ice Hockey national team, takes care of various world class athletes ranging from ironman triathletes to formula 1 drivers, she is the first female medical director (Chefärztin) in the Hirslanden Klinik, and she recently graduated from the international director's program at INSEAD. $\mathrm{Q}$

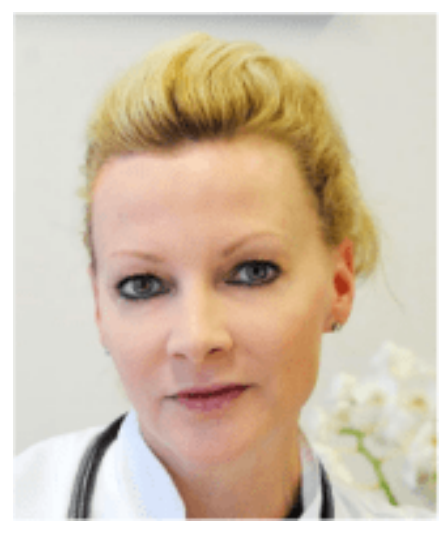

\section{References}

1. Ingram K. Why a female athlete should be your next leader. 23 September 2020. https://www.ey.com/en_gl/athlete-programs/whyfemale-athletes-should-be-your-next-leader (accessed 10 October 2020).

2. McKinsey Global Institute. The power of parity: how advancing women's equality can add $\$ 12$ trillion to global growth. September 2015.

3. Kotschwar B. Women, sports, and development: does it pay to let girls play? Peterson Institute for International Economics Policy Briefs. No. PB14-8, March 2014.

4. Brooke-Marcniak BA, De Varona D. Amazing things happen when you give female athletes the same funding as men. 25 August 2016.

https://www.weforum.org/agenda/2016/08/sustaining-the-olympic-legacy-women-sports-and-public-p 
olicy/ (accessed 08 October 2020). 